\title{
PROPOSAL OF LANDFILL SITE MODEL IN THE PARTICULAR TERRITORY
}

\author{
Ondrej Stopka ${ }^{1}$, Ivana Simková ${ }^{2}$ \\ ${ }^{1}$ Department of Transport and Logistics, Institute of Technology and Businesses in Ceske Budejovice \\ Okruzni 517/10, 37001 Ceske Budejovice, Czech Republic \\ Ph.: (+420) 387842188 \\ E-mail: stopka@mail.vstecb.cz
}

${ }^{2}$ Department of Road and Urban Transport, The Faculty of Operation and Economics of Transport and Communications, University of Zilina, Univerzitna 1, 01026 Zilina, Slovak Republic

Ph.: (+421) 415133523

E-mail: ivana.simkova@fpedas.uniza.sk

\begin{abstract}
Nowadays, waste logistics is a relevant element within the worldwide logistics system. This paper is focused on the proposal of the appropriate model of landfill site for disposal of municipal waste. This issue refers to waste logistics in urban areas. In this regard, three different alternative models of landfill sites are considered. Landfill site model can significantly influence the waste management productivity and effectiveness of the enterprise. In the paper, one of the decision-making problem methods is utilized. This particular method enables to assess each model of landfill site in relation to each of the specified criterion and order the models according to the achieved results.
\end{abstract}

Keywords: Landfill site, waste logistics, municipal waste, decision-making problem, urban area

\section{Introduction}

Waste is according to $\S 3$ of Act No. 185/2001 Coll., On waste, as amended (hereinafter referred to as the "Act"); any movable thing that the owner disposes of or intends or has duty to dispose of and belongs to a group of wastes listed in Annex 1 to this "Act".

The disposal of waste in accordance with the "Act" always takes place when a person passes the chattel, belonging to the groups of waste, for recovery or disposal under the "Act", or when a person passes it to another person authorized to collect or purchase the waste in accordance with the "Act", regardless of whether the transfer is without charge or paid. The disposal of wastes also occurs when the person alone removes the chattel belonging to a group of wastes.

The legal person whose activities produce waste or natural person authorized to do business whose business activities produce waste are the waste producers within the meaning of the "Act". The municipality is considered to be the originator of the waste for municipal waste (hereinafter referred to as MW), arising from the territory of the municipality, which has its origin in the activities of natural persons, which are not subject to the obligations of the originator. The municipality becomes the originator of the municipal waste when a natural person puts the waste at a designated location; the municipality will become the owner of this waste simultaneously.

\section{Waste Logistics in Urban Areas}

According to the "Act", municipal waste is all the waste generated within the municipality by the activity of natural persons and which is listed as a municipal waste (MW) in the implementing the regulation - Decree no. 381/2001 Coll., Waste Catalogue, with the exception of waste produced by legal entities or natural persons authorized to do business.

According to Decree no. 381/2001 Coll. (Eko-Kom, 2011), Waste catalog, each waste has its own catalog number. Municipal waste has No. 20 in this Decree and is divided into three groups and further into several subgroups.

\subsection{Municipal Waste and Its Production}

Production of municipal waste (Eko-Kom, 2011; Míka and Kučerková, 2014) in the Czech Republic is about 4 mil. tons/year. The main type of waste is mixed municipal waste and bulky waste, ie types of 
waste remaining after the sorting the usable components in systems of separate collection of waste. In improving the waste recovery and reducing the waste storage, it is an obvious potential for change in requirements for gathering and thereby the collection and transportation (distribution) of waste. To increase the utilization and reduce the storage of waste, it is necessary to extend the separate collection systems and build the new devices for a central treatment of Sorted residual municipal waste.

Overall, demands to increase the transportation performance for waste and its streamlining can be anticipated.

Table 1 contains the data on NO production in the Czech Republic in 2012 (tons/year).

Table 1. NO production in the Czech Republic in 2012 (tons/year) (Waste Management, 2012)

\begin{tabular}{|l|l|l|}
\hline Waste code & Waste name & $\begin{array}{l}\text { Waste production (A00) } \\
\text { (t/year) }\end{array}$ \\
\hline 200101 & Paper and paperboard & 259018,928 \\
\hline 200102 & Glass & 77859,541 \\
\hline 200108 & Biodegradable waste from kitchen and canteen & 14417,669 \\
\hline 200110 & Clothing & 948,051 \\
\hline 200111 & Textile materials & 5247,702 \\
\hline 200125 & Edible oil and fat & 2780,307 \\
\hline 200138 & Wood & 12139,742 \\
\hline 200139 & Plastics & 68931,391 \\
\hline 200140 & Metals & 97459,822 \\
\hline 200201 & Biodegradable waste & 130354,35 \\
\hline 200301 & Mixed municipal waste & 2812243,041 \\
\hline 200302 & Wastes from marketplaces & 14676,842 \\
\hline 200307 & Bulky waste & 383709,589 \\
\hline 200133,200134 & Batteries and accumulators & 1251,047 \\
\hline $200135,200136,200123,200121$ & $\begin{array}{l}\text { Products which are subject to recollection classified under } \\
\text { those codes }\end{array}$ & 14127,61 \\
\hline- & Other NO categorized in No. 20 & 5585,807 \\
\hline Total & & $\mathbf{3 9 0 0 7 5 1 , 4 3 9}$ \\
\hline
\end{tabular}

\subsection{Sources of Waste}

Main sources of waste are (Míka and Kučerková, 2014):

- Households (waste from citizens) - These wastes are collected in the municipality, which must ensure the collection, transport, disposal of municipal waste collection, transport, gathering and temporary storage of separated components of municipal waste. In addition to MW, municipalities pick over another waste as well - construction waste, tires, etc. According to Decree $3 / 2001$, On the management of municipal and construction waste within the city area, natural persons are obliged to gather, sort and transmit the MW, separately, to recovery (utilization) and disposal.

- Municipality or cities (waste generated within the municipality or city area) - Many services in the city or municipality area are provided by authorized person under the contract with the city or municipality. Mostly, these are technical services or other services dealing with the waste management.

- Organizations (other than municipalities and cities) - All the services such as banks, schools, medical facilities, shops, as well as offices, trades, etc. are included in this type of waste sources. All of the above mentioned organizations produce waste similar to municipal waste and therefore it is often classified in the same category.

In these areas, a lot of different kinds of waste are produced. Some of them are usually further processed (recycled), some of them are subject to recollection (this is mainly related to hazardous waste) and other can no longer be utilized. This last kind of waste is to be put to a landfill or burned in incinerators.

\subsection{Transportation of Municipal Waste}

Transportation of municipal waste includes both waste transportation from the place of its origin (eg.: household) to the place of its concentration (eg.: station of containers) as well as the transportation of waste from the place of its concentration to the disposal area.

Generally (Míka and Kučerková, 2014), transportation of municipal solid waste can be divided according to various criteria. The most common division is according to:

- Transport distance

- Used transport means 


\section{The Technique Used for the Collection and Transportation of Municipal Waste}

The selection of transport means for waste collection and transportation is adjusted to a wide range of waste containers. In the Czech Republic, there are universal superstructures, allowing the emptying all the basic types of containers - 110, 120, 240 and 11001 .

For the transportation of waste (Míka and Kučerková, 2014; Kampf, Gašparík, Kudláčková, 2012), various, for this purpose especially designed cars, are used. They can be divided into three groups:

- Collecting garbage trucks - for the garbage removal gathered in the standardized trash containers

- Carriers of the containers - for the garbage collected (gathered) in the garbage carriages

- Transport garbage trucks - for the long haul of garbage from transshipment stations

\section{Decision-making Problems}

Selecting the suitable landfill site model for disposal and dumping the municipal waste can be viewed as a decision-making problem in which the final decision is affected by a group of external factors. For the purpose of solving the decision-making problems (Klein, et al., 1993) the methods of multi-criteria analysis can be used. The decision means in a given situation choosing one option from a list of potentially viable variants against several criteria. Next to the list of criteria indirectly forming the objective of the decision analysis (Brožova, Houška, Šubrt, 2003), it is necessary to have a list of variants from which to choose.

Generally (Zavadskas, Turskis, 2011), the basic procedure for the multi-criteria analysis (evaluation of alternatives) includes six steps: (1) Identification of variants, (2) Establishment of a set of criteria, (3) Determination of criteria weightings, (4) Determination of criterion examples, (5) Partial evaluation of variants and (6) Selecting the most suitable variant.

A detailed description of methods (Fotr, et al., 2006; Zavadskas, Turskis, 2011) of decision-making can be found in literature dealing with this issue. There are a number of methods that are used for solving multi-criteria analysis issues. The simple ones (Klein, et al., 1993) do not take into account the weight of each criterion and therefore are not appropriate for this paper because in the group of criteria which influence the layout of handling space, significant differences in the importance of criteria exist.

\subsection{Determining the Criteria Weightings}

Determining the criteria weightings (Fotr, et al., 2006; Saaty, Vargas, Wendell, 1983) is closely related to the completeness of a set of criteria reflecting the essential characteristics of the alternative. This is usually a key step in the analysis of the model of multi-criteria analysis. The information obtained in any way is used to determine the preferential relations between alernatives depending on the objectives of the entire analysis.

Methods (Saaty, Vargas, Wendell, 1983; Zavadskas, Turskis, 2011) for the weightings determining can be divided according to the information we have on the preference of criteria.

\subsection{Selecting the Appropriate Alternative}

Methods (Brožova, Houška, Šubrt, 2003) for the alternative selecting are divided according to what information about the preference among the criteria they require for their work and methods in terms of weights and about the alternative in the form of a criteria matrix with cardinal values as well: (1) maximizing the benefits, (2) minimizing the distance from the ideal variant and (3) preferential relationship.

Specific methods (Brožova, Houška, Šubrt, 2003; Fotr, et al., 2006; Saaty, 1983) for the most appropriate alternative selecting: Lexicographical method, Permutation method, ORESTE method, TOPSIS method, Weighted Sum Analysis - WSA, AHP method, Ardolana method and other.

\section{Data and Methods}

\subsection{Identification of Alternatives}

In phase one, it is necessary to identify a set of alternatives from which the final solution will be selected. The following different types of landfill site models were identified.

\subsubsection{Landfill Site Model A}

In this model, municipal waste is dumped horizontally, that is parallel to the main road infrastructure and ancillary roads as shown in Figure 1. 


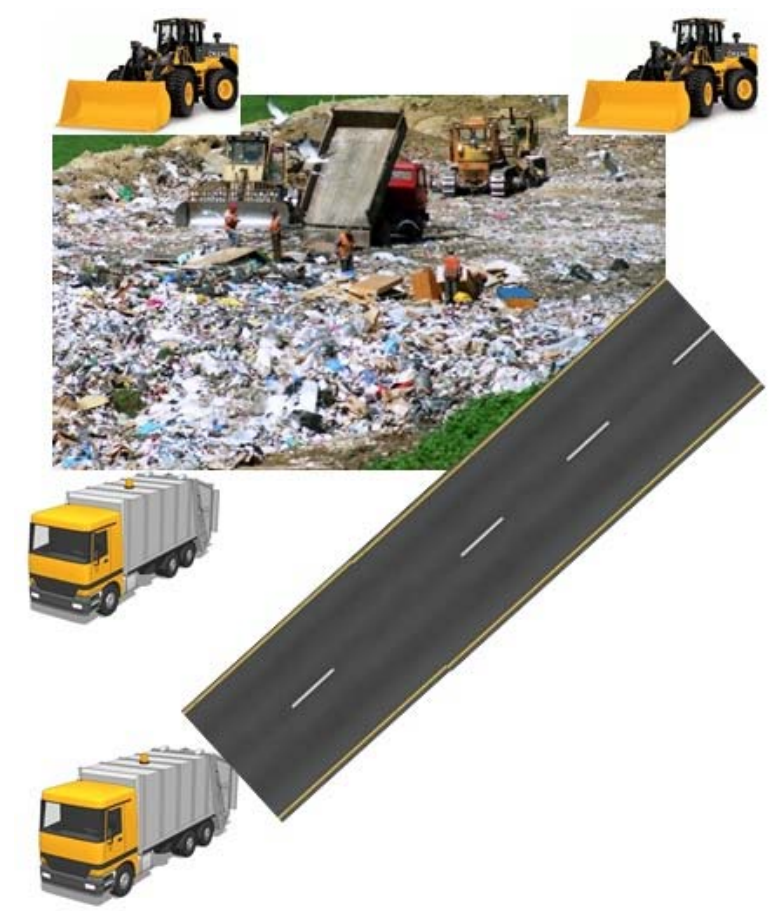

Figure 1. Landfill site model A

All garbage trucks serve only in the horizontal direction (parallel to the main road infrastructure). Generally, each section of landfill site is served by one garbage truck and one bulldozer. All horizontal ancillary roads are unidirectional and are used both for unloading of garbage trucks and the transit.

\subsubsection{Landfill Site Model B}

In this model of landfill site, municipal waste is dumped vertically, that is perpendicularly to the main road infrastructure and main railway track as shown in Figure 2.

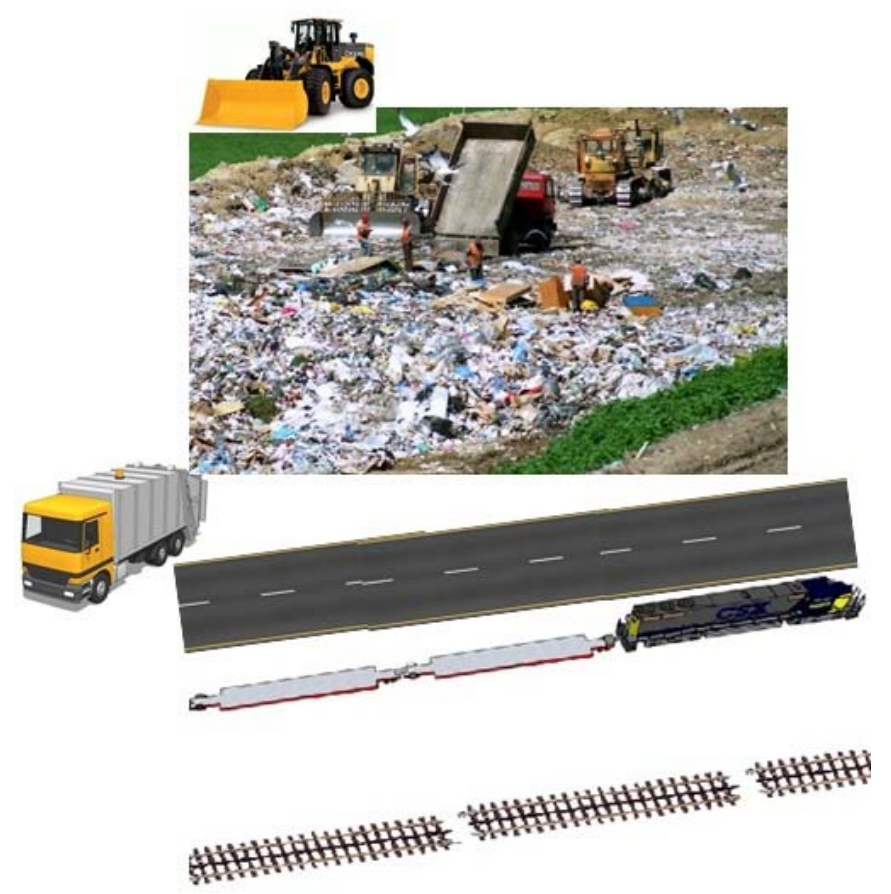

Figure 2. Landfill site model B 
There are ancillary horizontal roads which are bidirectional and are used only for unloading of garbage tracks (not for transit of vehicles). Roads in this landfill site model provide a faster access to individual sections. The same garbage truck and bulldozer can serve in various sections of landfill site (due to bidirectional ancillary roads).

\subsubsection{Landfill Site Model C}

Fourth model presents a combined form of previous two models (Figure 3). Municipal waste is dumped vertically to the main road infrastructure and horizontally to another main road infrastructure, ancillary roads and main railway track.

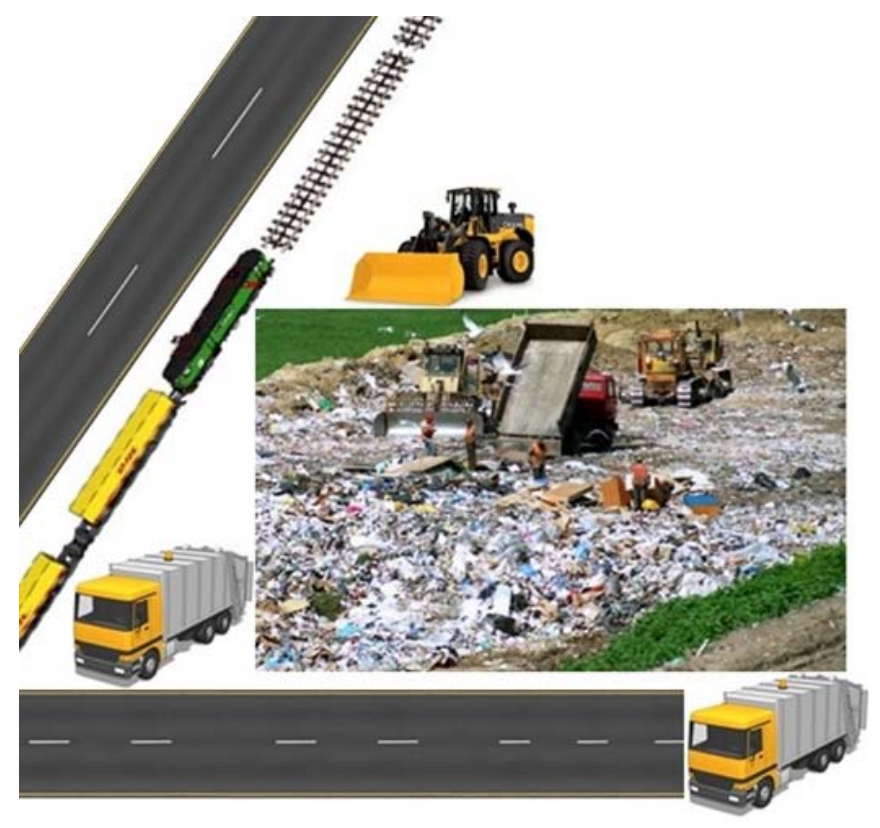

Figure 3. Landfill site model C

In this model, ancillary horizontal roads are bidirectional and are used both for unloading of garbage tracks and for the transit as well. Roads in this landfill site model provide the fastest access to individual sections (compared to the other landfill site models). The same garbage truck and bulldozer can serve in various sections of landfill site.

Garbage trucks travel a shorter distance, bulldozers are utilized more but the traffic is more because of the connection to two types of main road infrastructure.

\subsection{Identification of Criteria}

Phase two (Fotr, et al., 2006; Kampf, Gašparík, Kudláčková, 2012) of the decision-making problem process includes an identification of the set of criteria which affects whole process in the context of selecting the alternatives. The rational creation of evaluation criteria significantly depends on a thorough knowledge of the object of evaluation and on a systemic understanding of its structure and its functions. The set of criteria (Fotr, et al., 2006; Saaty, Vargas, Wendell, 1983) must be comprehensive i.e. it must reflect the essential characteristics of the objects (alternatives). If the latter is not the case, a big distortion in the results may occur.

It is necessary to differentiate the criteria according to the type of preference: increasing preference (maximization, profit), decreasing preference (minimization, loss) and alternating preference - preference changes when a certain value is achieved.

Decision-making for a typical landfill site model requires taking more than one criterion into account. After determining the objectives of the available knowledge analysis, relevant to this paper, four criteria primarily from transport-economic fields were identified: (a) investment costs of the landfill site building (costs), (b) minimum unloading time of garbage trucks and movement speed of bulldozers (U\&M - unloading time and movement speed), (c) minimization of ancillary road infrastructure to create greater dump capacity and better accessibility of dump sections (D\&A - dump capacity and accessibility), and (d) amount of traffic and extend of space needed to build a whole landfill site in a particular territory (T\&S traffic and extend of space). 


\subsubsection{Investment Costs of the Landfill Site Building (Costs)}

Considering the assumptions in alternative $\mathrm{C}$, ancillary horizontal roads are connected to two types of main road infrastructure (vertical and horizontal) and there can be more bulldozers. Apparently, that is the reason why this landfill site model has the highest cost compared to the other ones.

However, this model needs the least number of garbage trucks as the distance for trucks travel is less and more bulldozers are there to serve.

Based on the above mentioned assumptions, alternative $\mathrm{A}$ is next and alternative $\mathrm{B}$ is the least cost.

\subsubsection{Unloading Time of Garbage Trucks and Movement Speed of Bulldozers (U\&M)}

Alternative $\mathrm{C}$ has the minimum unloading time with a fastest access to individual landfill site sections, compared to the other alternatives. Model B is the second in the order and the highest unloading time and the slowest access to individual sections belongs to alternative A - due to unidirectional ancillary roads.

\subsubsection{Dump Capacity and Accessibility of Dump Sections (D\&A)}

Alternative $\mathrm{B}$ is the most capacious (since the smallest number of horizontal ancillary roads) followed by alternative $\mathrm{A}$ and $\mathrm{C}$. In model B, ancillary roads only for unloading of garbage tracks are used and the connection to the horizontal main road infrastructure is omitted so the dump capacity is increased. Also the capacity of the model A is higher than model $\mathrm{C}$ because of the less road infrastructure used for transit or unloading.

In terms of using the bulldozers and garbage trucks in both import and export area (accessibility) of the landfill site, alternative $\mathrm{C}$ is the best. Considering the existence of bidirectional ancillary roads, alternative $\mathrm{B}$ is suitable in terms of accessibility as well. On the other hand, transit ancillary roads are omitted in this model. Due to the existence only the unidirectional ancillary roads, alternative $\mathrm{A}$ is the worst accessible.

\subsubsection{Traffic and Space Needed to Build a Whole Landfill Site (T\&S)}

As mentioned above, because of the connection to two types of main road infrastructure, alternative $\mathrm{C}$ has the greatest amount of traffic. Alternative $\mathrm{A}$ is the second worst and due to the omitted transit ancillary roads, alternative $\mathrm{B}$ has the least traffic.

In terms of size of the space needed to build the particular model of landfill site, models A and B are the same good. These models of landfill site have a connection to either horizontal or vertical main road infrastructure. Construction of the model $\mathrm{C}$ takes the most space due to the largest number of connecting infrastructure.

\subsection{Determining the Key Methods}

Selecting the suitable method (Klein, et al., 1993; Saaty, 1983) depends on the perspective of the investigator interested in the subject. There are many different methods of decision-making problems which can help in the selecting the landfill site model. In practice, however, many methods cannot be used because they do not allow for the processing of all the intricacies intended in this matter and the fact that we do not know the details of the users of landfill sites, which we could have analyzed.

On this basis (Saaty, 1986), it was decided to use the Analytic Hierarchy Process (AHP) method, which appears to be relatively easy to handle and apply to so complex and difficult task of selecting the landfill site model.

In its calculation, the AHP method uses criteria with set weightings. Again, there are several methods to determine the criteria weightings. For the purposes of this paper basis (Saaty, 1986), the Saaty pairwise comparison method was chosen. A number of criteria have lesser or greater effect on the model selection. It was therefore necessary to choose such a method which allows human judgment to determine the relationship preference between two criteria being compared. Furthermore (Klein, et al., 1993; Saaty, Vargas, Wendell, 1983), the Saaty method allows for the detailed division of these preferences.

\subsubsection{Saaty Pairwise Comparison Method}

This is a method (Saaty, 1983) of quantitative pairwise comparison of criteria. For the evaluation of paired comparison of criteria, a $9(1,3,5,7,9)$ point scale is used. It is also possible to use intermediate values - 2,4,6,8. Matrix elements (Bonissone, 1998; Saaty, Vargas, Wendell, 1983; Zavadskas, Turskis, 2011) $S=\left(S_{i j}\right)$ are interpreted as estimates of the proportion of the weights of the $i$-th and $j$-th criteria.

The researcher (Bonissone, 1998; Saaty, Vargas, Wendell, 1983) compares each pair of criteria and enters the sizes of preferences of $i$-th in relation to the $j$-th criterion in the Saaty matrix $S=\left(s_{i j}\right)$. In case $j$-th 
criterion is preferred above that of the $i$-th criterion, inverse values are entered into the Saaty matrix $\left(s_{i j}=1 / 3\right.$ for low preference, $s_{i j}=1 / 5$ for strong preference, etc.).

This already indicates the basic characteristics of the Saaty matrix. Saaty (1983) designed several numerically very simple ways by which the weights can be estimated. Vector of their values is denoted as $v=\left(v_{1}, v_{2}, \ldots, v_{k}\right)$. The most commonly used method of calculating weights is the normalized geometric mean of a row in a Saaty matrix (Saaty, Vargas, Wendell, 1983), the procedure is sometimes called "logarithmic least squares method".

The "priority vector" i.e. the normalized weight is calculated for each criterion using the geometric mean of each row in the matrix divided by the sum of the geometric means of all the criteria.

Calculating the geometric mean of each row of the matrix $\mathrm{S}$ (Formula 1):

$g_{i}=\sqrt[k]{\prod_{j=1}^{k} s_{i j}}$, for $i, j=1,2, \ldots, k$

where: $g_{i}$ - geometric mean; $s_{i j}$ - elements of Saaty matrix; $\Pi$ - product of values of Saaty matrix elements.

Normalization of the geometric mean (Formula 2):

$v_{i}=\frac{g_{i}}{\sum_{i=1}^{k} g_{i}}$, for $i=1,2, \ldots, k$

where: $\mathrm{v}_{\mathrm{i}}$ - normalized geometric mean; $\mathrm{g}_{\mathrm{i}}$ - geometric mean; $\sum$ - sum of geometric means' values.

\subsubsection{Analytic Hierarchy Process Method}

The Analytic Hierarchy Process (AHP) method, first suggested by Saaty (1983) more than three decades ago, is one of the widely used multi-criteria decision-making methods. AHP (Saaty, 1986; Saaty, 1990; Saaty, 2008) can effectively handle both qualitative and quantitative data to decompose the problem hierarchically where the problem is broken down thoroughly and its related sub-elements with regards to the hierarchical level are listed in relation from the overall objective to the sub-objectives. General AHP procedure is composed of four main phases (Figure 4):

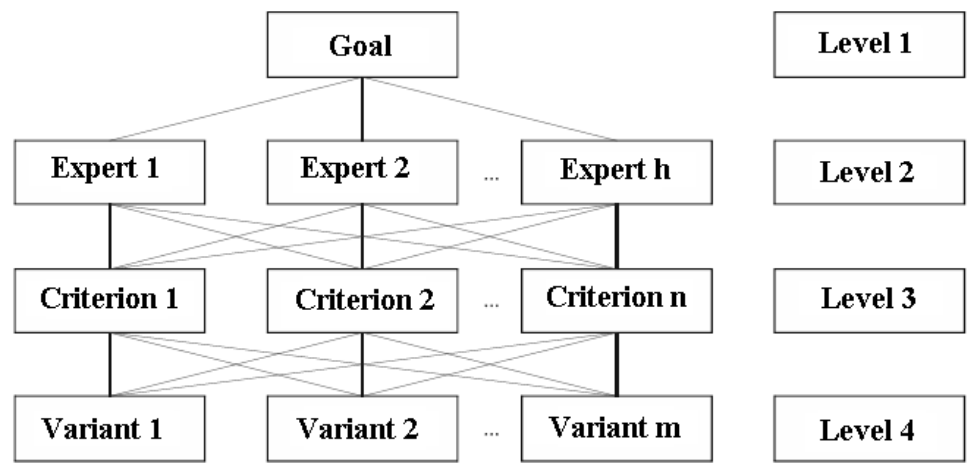

Figure 4. The Analytic Hierarchy Process structure (Saaty, 1990)

- Hierarchical problem decomposition: Identifying the decision problem and overall goal/objective - the problem is decomposed into sub-elements hierarchically (which are structured at different levels in the form of a hierarchy, from the top through the intermediate to the lower-level, which usually contains a finite number of decision elements),

- Evaluation phase: the relative importance of each element at a particular level is measured by a procedure of pair-wise comparison. Decision makers provide numerical values for the priority of each element using a rating scale,

- Synthesis of alternatives (ranking): the priority weights of elements at each level are computed using an eigenvector or least square analysis.

- Result: the above process is repeated for each level of the hierarchy until a decision is finally reached by overall composite weights.

The goal (Saaty, 1990) is to select the alternatives that results in the greatest value of the objective function. This is a compensatory optimization approach. 


\section{Calculations and Results}

\subsection{Determining the Criteria Weightings}

As mentioned above, the determining the criteria weightings is realized using the Saaty pairwise comparison method. The first step of the Saaty method (Saaty, 1983; Saaty, Vargas, Wendell, 1983) is to determine the relationship between each pair of criteria when the level of preference is determined in a spot range between 1-9. This is determined as follows:

- To ensure the greatest possible objectivity in the selecting the appropriate landfill site model, 10 experts from the field of waste logistics were asked to determine preferences between individual criteria. Each of the ten experts set a level of significance for each pair of criteria.

- For each element of the matrix, a product of the sub-matrices of all experts was established and then the average was calculated.

Subsequently, elements of the Saaty method were used for further calculations. The individual values obtained from a procedure of the criteria weightings determining and the values obtained for the individual criterion in the intermediate calculations and the final values of the vector of weights of individual criterion are given in Table 2 .

Table 2. Values obtained using the Saaty method

\begin{tabular}{|c|c|c|c|c|c|}
\hline & Criterion & 1 & 2 & 3 & 4 \\
\hline 1 & Costs & 1 & 3 & 3 & 5 \\
\hline 2 & U\&M & $1 / 3$ & 1 & $1 / 2$ & 3 \\
\hline 3 & D\&A & $1 / 3$ & 2 & 1 & 4 \\
\hline 4 & $\mathrm{~T} \& \mathrm{~S}$ & $1 / 5$ & $1 / 3$ & $1 / 4$ & 1 \\
\hline Product of values & & 45 & $1 / 2$ & $8 / 3$ & $1 / 60$ \\
\hline Geometric mean & & 2.590 & 0.841 & 1.278 & 0.359 \\
\hline Normalized geometric mean & & 0.511 & 0.166 & 0.252 & 0.071 \\
\hline
\end{tabular}

Explanatory notes:

U\&M - unloading time and movement speed,

D\&A - dump capacity and accessibility,

$T \& S$ - amount of traffic and extend of space.

The final product of a consistent Saaty pairwise comparison method is the overall priority vector (normalized geometric mean) of the criteria as illustrated in the last row of Table 2.

\subsection{Selecting the Appropriate Alternative}

It was decided that for the purpose of this paper, one of the decision-making problem methods, known as Analytical Hierarchy Process, is applied. In our case, it enables to evaluate the suitability of three identified alternatives of landfill site models. The outcome of this method (Kampf, Lizbetin, Lizbetinova, 2012; Saaty, 1990) is an order of three landfill site models based on the overall preferences expressed by the experts' evaluation.

Assigning the judgment of decision makers (experts) to each of the criteria was the first step of this method. Subsequently (Kampf, Lizbetin, Lizbetinova, 2012; Saaty, 2008), according to the AHP process, a comparison of individual models between them by each determined criterion was performed. And again, ten experts were asked to determine preferences between individual alternatives by each criterion. Each of the ten experts set a level of significance for each pair of alternatives by the corresponding criterion. And for each element of the matrixes assessment (Saaty, 1990), a product of the sub-matrices of all experts was established and then the average was calculated.

All comparisons of the models for each criterion (cost, U\&M, D\&A, T\&S) are presented in the following tables (Table 3 - 6).

Table 3. The comparison matrix of the models for cost

\begin{tabular}{|l|l|l|l|}
\hline Cost & Model A & Model B & Model C \\
\hline Model A & 1 & $1 / 3$ & 2 \\
\hline Model B & 3 & 1 & 5 \\
\hline Model C & $1 / 2$ & $1 / 5$ & 1 \\
\hline Geometric mean & 0.874 & 2.466 & 0.464 \\
\hline Normalized geometric mean & 0.230 & 0.648 & 0.122 \\
\hline
\end{tabular}


Table 4. The comparison matrix of the models for unloading time and movement speed

\begin{tabular}{|l|l|l|l|}
\hline U\&M & Model A & Model B & Model C \\
\hline Model A & 1 & $1 / 2$ & $1 / 4$ \\
\hline Model B & 2 & 1 & $1 / 2$ \\
\hline Model C & 4 & 2 & 1 \\
\hline Geometric mean & 0.5 & 1 & 2 \\
\hline Normalized geometric mean & 0.143 & 0.286 & 0.571 \\
\hline
\end{tabular}

Table 5. The comparison matrix of the models for dump capacity and accessibility

\begin{tabular}{|l|l|l|l|}
\hline D\&A & Model A & Model B & Model C \\
\hline Model A & 1 & $1 / 5$ & $1 / 2$ \\
\hline Model B & 5 & 1 & 4 \\
\hline Model C & 2 & $1 / 4$ & 1 \\
\hline Geometric mean & 0.464 & 2.714 & 0.794 \\
\hline Normalized geometric mean & 0.117 & 0.683 & 0.200 \\
\hline
\end{tabular}

Table 6. The comparison matrix of the models for amount of traffic and extend of space

\begin{tabular}{|l|l|l|l|}
\hline T\&S & Model A & Model B & Model C \\
\hline Model A & 1 & $1 / 4$ & 3 \\
\hline Model B & 4 & 1 & 7 \\
\hline Model C & $1 / 3$ & $1 / 7$ & 1 \\
\hline Geometric mean & 0.909 & 3.037 & 0.362 \\
\hline Normalized geometric mean & 0.211 & 0.705 & 0.084 \\
\hline
\end{tabular}

In total, four criteria were determined and for each one its weight was calculated. This weight must be subdivided among the alternatives. Weight of each criterion and also alternatives' weights according to these criteria were calculated (see Table 2 - 6).

\section{Conclusions}

In order to determine the overall order of alternatives, sum of values of each alternative by the individual criterion multiplied by the weight of the corresponding criterion was counted. Subsequently, models were placed in descending order whereby the order of alternatives was identified (Table 7).

The AHP method of the decision-making problem has convinced to be useful tool in this matter on the most appropriate scenario in landfill site model among four proposed alternatives.

The horizontal type as the first layout, then the modified form of previous one would be the second layout, the third layout is a vertical type and the fourth layout is a combined form of previous layouts.

Resulting weightings of each layout according to each criterion and the order of layouts are in the following Table 7.

Table 7. Resulting weightings and the order of alternatives

\begin{tabular}{|l|l|l|l|l|}
\hline Model Criterion & Cost & U\&M & D\&A & T\&S \\
\hline Model A & 0.230 & 0.143 & 0.117 & 0.211 \\
\hline Model B & 0.648 & 0.286 & 0.683 & 0.705 \\
\hline Model C & 0.122 & 0.571 & 0.200 & 0.084 \\
\hline Criteria weightings & 0.511 & 0.166 & 0.252 & 0.071 \\
\hline & & & & \\
\hline Sum of values for models (A,B,C) & 0.186 & 0.601 & 0.213 & \\
\hline Order of models & $\mathbf{3 .}$ & $\mathbf{1 .}$ & $\mathbf{2 .}$ \\
\hline
\end{tabular}

In this regard, the following performance criteria have been considered in the decision making process: (a) costs, (b) unloading time and movement speed, (c) dump capacity and accessibility, and (d) traffic and extend of space.

Ultimately, having considered the above results of the calculations, in the overall order of alternatives, model $B$ appears to be the most appropriate landfill site model in the particular territory followed by model $\mathrm{C}$ and model $\mathrm{A}$. The used method allows for the reducing and adding in the number of criteria that are taken into account in search of solutions.

Preferences differ from one decision maker to another (Kampf, Gašparík, Kudláčková, 2012); therefore, the outcome depends on who is making the decision and what their goals and preferences are. 
Furthermore, in future, the managers and operators of landfill site should be more involved with nonmonetary issues and decision criteria such as environmental issues like air and noise pollution etc.

\section{References}

1. Brožova, H., Houška, M., Šubrt, T. (2003) Modely pro vícekriteriální rozhodování. Česká zemědělská univerzita v Praze, Prague: CREDIT, ISBN 80-213-1019-7, 178 p.

2. Bonissone, P. P. (1998) Determination of Weight Vector (cardinal ratio scale) from Pairwise Comparisons. [online].

3. Eko-Kom. (2011) Municipal waste. [online]. Prague. Available at: http://www.ekokom.cz.

4. Fotr, J. et al. (2006) Manažerské rozhodování, Vyd. 1. Praha: Ekopress, ISBN 80-86929-15-9. 409 p.

5. Kampf, R., Gašparík, J., Kudláčková, N. (2012) Application of different forms of transport in relation to the process of transport user value creation. Periodica Polytechnica Transportation Engineering, $40(2)$, pp. $71-75$.

6. Kampf, R., Lizbetin, J., Lizbetinova, L. (2012) Requirements of a transport system user. Communications, 14(4), pp. 106-108.

7. Klein, G. A. et al. (1993) Decision making in action: Models and methods. Westport, CT, US: Ablex Publishing, $480 \mathrm{p}$.

8. Míka, J., Kučerková, M. (2014) Logistics of the Disposal of Municipal Waste. In: LOGI - Scientific Journal on Transport and Logistics, Institut Jana Pernera, o.p.s., and Institute of Technology and Business in České Budějovice, Czech Republic, 1/2014, ISSN 1804-3216, pp. 88-92.

9. Saaty, T. L. (1983) Priority Setting in Complex Problems, in Hansen, P. (Hrg.), Essays and Surveys on Multiple Criteria Decision Making. In: Proceedings of the Fifth International Conference on Multiple Criteria Decision Making, Berlin/Heidelberg/NewYork: Springer-Verlag, pp. 140-155.

10. Saaty, T. L. (1986) Axiomatic Foundation of the Analytic Hierarchy Process. Management Science, 32(7), pp. 841-847.

11. Saaty, T. L. (1990) Decision Making for Leaders: The Analytic Hierarchy Process for Decisions in a Complex World, RWS Publications, Pittsburgh, Pennsylvania, 292 p.

12. Saaty, T. L. (2008) Decision making with the analytic hierarchy process. International Journal of Services Sciences, 1(1), pp. 83-98.

13. Saaty, T. L., Vargas, L. G., Wendell, R. E. (1983) Assessing Attribute Weights by Ratios. Omega The International Journal of Management Science, 2(1), pp. 9-13.

14. Waste Management. (2012) Waste Management Information System. [online]. Available at: http://www1.cenia.cz/www/odpady/isoh.

15. Zavadskas, E. K., Turskis, Z. (2011) Multiple criteria decision making (MCDM) methods in economics: an overview. Technological and Economic Development of Economy, 17(2), ISSN 20294913, pp. 397-427. 